\title{
Effects of cingulate cortex lesions and morphine premedication on morphine intake in rats*
}

\author{
CLINTON L. TRAFTON and MARCIA KAHN \\ University of Arizona, Tucson, Arizona 85721
}

\begin{abstract}
Groups of rats were given bilateral lesions in the cingulate cortex and then half were subjected to a regimen of chronic morphine injections, while the other half received no premedication. Morphine-oriented behavior was indexed by a learned preference for a bitter morphine $\mathrm{HCl}$ solution. Bilateral anterior cingulate cortex lesions resulted in a decrement in the acquisition of drug-oriented behavior, while premedication produced an enhancement of morphine intake.
\end{abstract}

In the search for an explanation of drug-oriented behavior, two main lines of argument have developed. The first postulates that the effects of the drug are pleasurable or reinforcing; thus drug intake is more likely to occur again. It has been shown, for example, that monkeys will learn to self-administer morphine before sufficient time has elapsed for dependence to develop (Deneau, Yanagita, \& Seevers, 1969). The second type of hypothesis is that opiate intake, at least in dependent animals, is mainly a type of avoidance learning. It is argued that withdrawal effects in drug-deprived rats previously rendered dependent on morphine serve as noxious stimuli. Drug-oriented behavior, which serves to reduce these withdrawal symptoms, is seen as a type of active avoidance. This theory is supported by experiments (Nichols, 1965) in which dependent rats are given morphine injections to reduce withdrawal symptoms. These animals tended to decrease their morphine intake significantly.

It has been shown (Fox, Kimble, \& Lickey, 1964; Thomas \& Slotnick, 1962; Trafton, 1967) that limbic cortex lesions produce decrements in avoidance learning, and Foltz and White (1957) and Foltz (1959) have shown that cingulate lesions in primates modify withdrawal behavior. Trafton and Marques (1971) have shown that cingulate cortex lesions also produce decrements in morphine-oriented behavior in rats. They argue that since lesions producing avoidance learning deficits also produce decrements in morphine intake by dependent rats, the avoidance model of opiate intake is, at least partially, supported.

The present study was designated to examine further the effects of cingulate lesions on morphine-oriented behavior in rats. Theoretically, if cingulate lesions produce decrements in avoidance learning, and if this inability to respond to noxious stimuli (withdrawal symptoms) accounts for decrements in morphine intake (Trafton \& Marques, 1971), then such decrements should only be seen in drug-dependent rats. Animals that

\footnotetext{
*Requests for reprints should be sent to Clinton L. Trafton, Department of Psychology, University of Arizona, Tucson, Arizona 85721. This research was supported in part by Public Health Service Grant No. 1-R01-MH20971.
}

are not dependent on opiate drugs should show normal morphine intake patterns. However, if nondependent rats also show morphine intake decrements following cingulate lesions, the effect may be due to the effect of the lesions on positive reinforcement or on other aspects of morphine intake, since withdrawal symptoms should be nonexistent.

\section{EXPERIMENT I}

Method

\section{Subjects}

Thirty-five naive Sprague-Dawley male albino rats, weighing from 297 to $438 \mathrm{~g}$, served as Ss. The rats were individually housed in wire cages with food (Purina Rat Chow) freely available throughout the experiment.

\section{Procedure}

Four groups of Ss were randomly formed, constituting a 2 by 2 design. There were two types of surgery (anterior cingulate cortex lesions and control operations) and two types of drug preparation (nonpremedicated and premedicated with morphine). Group $\mathrm{CP}(\mathrm{N}=7$ ) received cingulate lesions and morphine premedication before testing. Group CNP $(\mathrm{N}=9)$ received cingulate lesions and saline injections. Group ContP $(\mathrm{N}$ =9) received control operations and was premedicated with morphine injections. Group ContNP $(\mathrm{N}=10)$ received control operations and saline injections. All four groups were tested for morphine intake.

\section{Surgical Procedure}

All Ss were given atropine sulfate to reduce respiratory tract secretions before surgical anesthesia with sodium pentobarbital ( $35 \mathrm{mg} / \mathrm{kg}$, IP). Groups CP and CNP received bilateral lesions in the anterior cingulate cortex produced electrolytically by $1.0-\mathrm{mA}$ anodal current applied through a stereotaxically guided stainless steel electrode. The lesions were made through closely spaced holes drilled in the skull $0.6 \mathrm{~mm}$ lateral to and along the midline; the current was applied for $15 \mathrm{sec}$ at each electrode site. The lesion targets extended $5.5 \mathrm{~mm}$ anterior from bregma to produce a continuous ablation of the anterior midline cortex. Groups ContP and ContNP were anesthetized and holes were bored in the skulls for the control operations, but no brain damage was induced. 


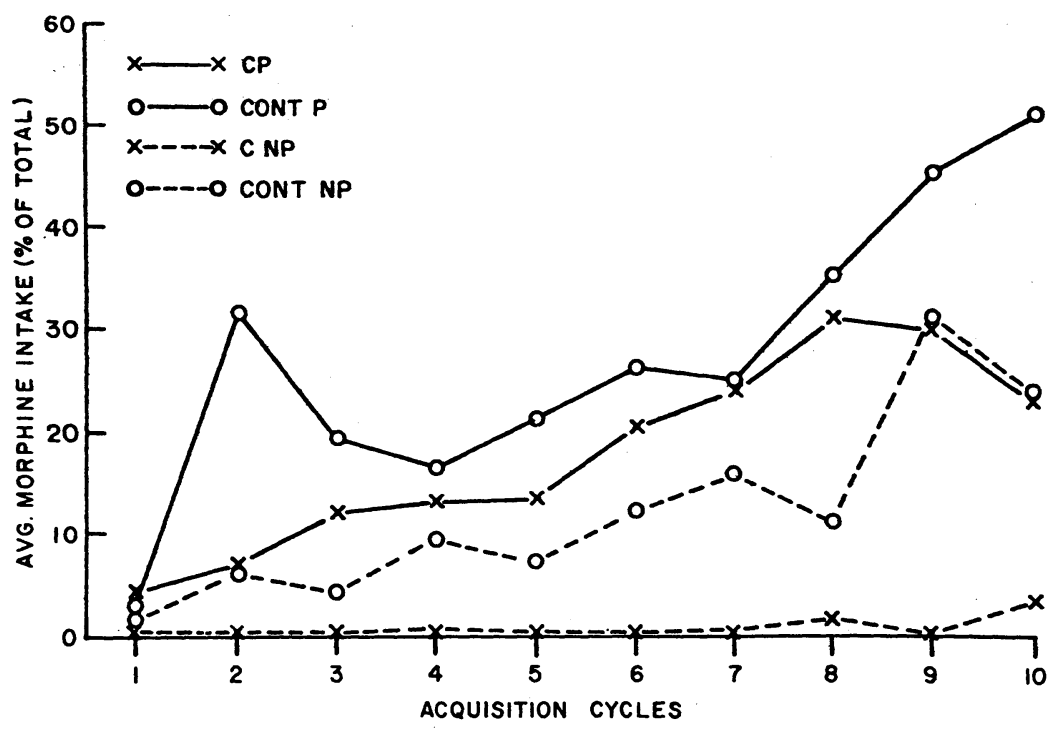

Fig. 1. Average morphine solution intake on the forth (choice) day of the acquisition training cycles, expressed as percent of total fluid ingested.

\section{Addiction Tests}

After 2 weeks of postoperative recovery, Groups CP and ContP were treated according to a modification of the technique used by Nichols (1965) to induce morphine addiction. Subcutaneous injections of morphine were given twice daily. Twenty $\mathrm{mg} / \mathrm{kg}$ body weight of morphine was given the first day $(10 \mathrm{mg} / \mathrm{kg}$ per injection), $30 \mathrm{mg} / \mathrm{kg}$ the second day, and so on, up to a maximum of $70 \mathrm{mg} / \mathrm{kg}$. Injections were continued for a total of 20 days. At the end of 20 days, injections were discontinued and instrumental morphine-directed behavior was evaluated during 104-day training cycles, each consisting of $24 \mathrm{~h}$ of fluid deprivation, $24 \mathrm{~h}$ during which a morphine solution alone $(0.5 \mathrm{mg}$ morphine $\mathrm{HCl}$ per milliliter water $)$ was available, $24 \mathrm{~h}$ with tap water alone, and $24 \mathrm{~h}$ during which preferences were measured when both water and morphine solutions were available. The right-left placement of drinking bottles was randomized.

\section{Results}

\section{Oral Intake}

Cingulate lesions (Groups CP and CNP vs Groups ContP and ContNP) produced significant decreases in morphine-directed behavior during the days when only morphine was available and also during the choice days when morphine and water were both available. Figure 1 presents the intake curves for all groups on the fourth (choice) days of each of the 10 testing cycles. During the early cycles, all groups drank very little of the morphine solution relative to their total fluid intake on choice days, and then (with the exception of Group CNP) showed a gradual increase in drug intake as testing continued. This is consistent with previous findings of Nichols, Headlee, and Coppock (1956), Stolerman and Kumar (1970), and Trafton and Marques (1971). When the intake data were expressed as percentages showing morphine intake relative to total (water plus morphine), analysis of the median intake on Day 4 of the last five cycles indicates that Groups CP and CNP drank significantly less morphine than Groups ContP and ContNP (Kruskal-Wallis $\mathrm{H}$ test, $\mathrm{p}<.03$ ). In a comparison of Groups $\mathrm{CP}$ and ContP on the last 5 choice days, Group CP consistently drank less morphine than Group ContP, but this difference is not significant. On the very last of the 10 choice days, it was found that Group ContP drank an average of 51.3\% morphine solution, Group CP drank 23\% morphine; Group ContNP's intake was $23.3 \%$ morphine, and that of Group CNP was 3.7\% morphine. Analysis of the median intake on Day 4 of the last five cycles also indicates that the premedicated groups ( $\mathrm{CP}$ and ContP) drank significantly more morphine than the nonpremedicated groups ( $\mathrm{H}$ test, $\mathrm{p}<.05$ ).

Rats with cingulate lesions also drank less morphine solution than the control rats on the second day of the training cycles, when only morphine was available. Figure 2 presents the average morphine intake for all groups on the second day of each of 10 testing cycles. A statistically reliable lesion effect $(\mathrm{H}$ test, $\mathrm{p}<.03)$ was found when the median intake of Groups CP and CNP was compared to that of Groups ContP and ContNP for the last five trials. This effect is due primarily to the low intake of the nonpremedicated lesioned animals, although both nonpremedicated groups ingested less morphine. Analysis of intake on the morphine-only day also shows a large difference between the median intake of the premedicated groups and the nonpremedicated groups ( $\mathrm{H}$ test, $\mathrm{p}<.01$ ), with the premedicated groups ingesting more morphine. These results support earlier findings, which show that premedication can facilitate the development of morphine-seeking behavior (Nichols, Headlee, \& Coppock, 1956; Nichols \& Davis, 1959).

\section{Discussion}

Rats with bilateral anterior cingulate cortex lesions consistently show less opiate-directed behavior than rats 
Fig. 2. Average morphine solution intake on the first (morphine only) day of the acquisition cycles.

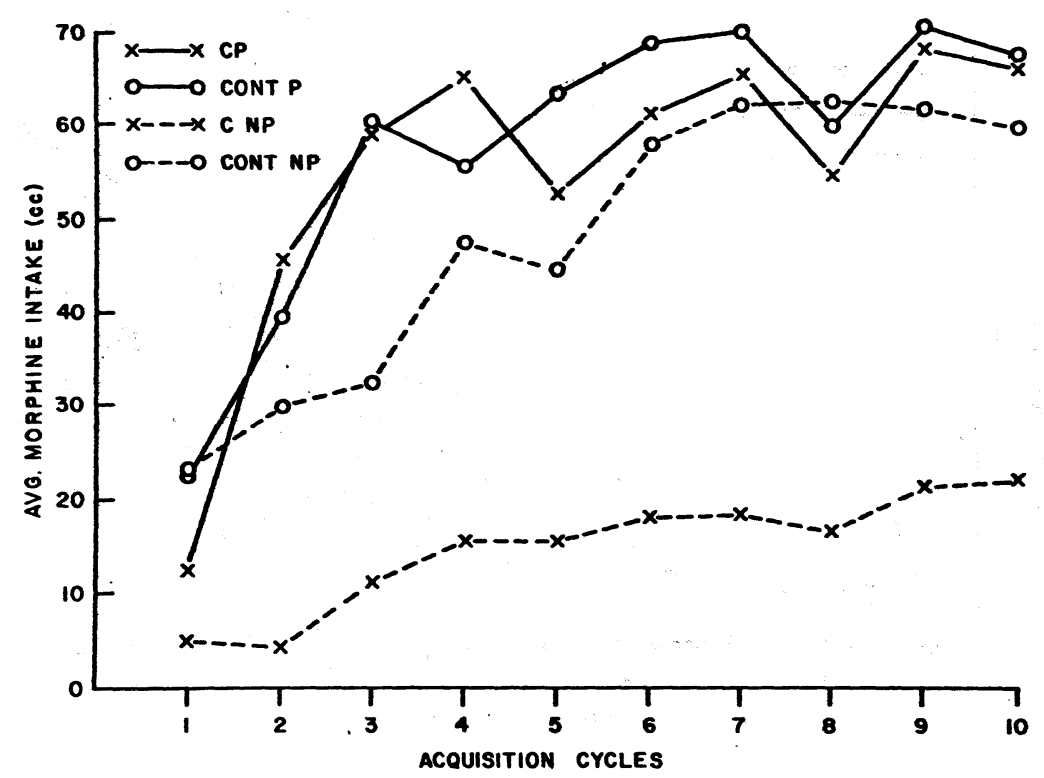

with control operations. This is true whether the animals received repeated morphine injections before testing or were nonpremedicated. The effect of the lesion on nonpremedicated rats is consistent with an argument that cingulate lesions produce a decrement in behavior which is oriented toward the pleasurable or rewarding aspects of the drug. That morphine acts as a reinforcer is shown by the gradually increasing drug intake of nonpremedicated animals on choice days (Fig. 1). In fact, both the present results and those of Trafton and Marques (1971) can be accounted for by arguing that cingulate lesions render the effects of morphine less reinforcing. Premedication would simply produce a tolerance effect such that more morphine is required to produce pleasurable or reinforcing effects, and increased intake is the result. The argument of Trafton and Marques (1971) that cingulate lesioned animals develop less severe withdrawal symptoms (or alternatively, that they cannot avoid such symptoms effectively) is unnecessary, even though such an argument can be supported as well.

The issues of dependency and tolerance raised by these arguments assume, of course, that the premedication procedures used are sufficient to produce dependency. No independent measures of dependency or tolerance were taken by Trafton and Marques (1971) or in the present research. When rats were shifted from twice daily injections to oral intake tests, however, diarrhea and $10 \%-15 \%$ weight loss were commonly seen selectively in premedicated rats, both lesioned and nonlesioned, in both studies.

In order to obtain further information about the possible effects of cingulate cortex lesions on affective states, two further studies were conducted. The first simply tests the same four groups of rats in a simple two-bottle preference test using a sugar solution vs plain tap water. If a "general affective dullness" results when cingulate lesions are induced, perhaps such rats will show less interest in a sweet solution under need-free conditions. The second additional study, also a preference test, pitted two bitter quinine solutions against each other in order to assure us that the cingulate-lesioned animals could in fact, make taste discriminations similar to those required in the morphine vs water preference tests just discussed, but when the solutions do not contain psychoactive drugs.

\section{EXPERIMENT II}

\section{Method}

Two weeks following the last preference tests of Experiment I, five daily two-bottle preference tests were conducted using $1.0 \%$ sugar (commerical cane sugar, $1.0 \mathrm{~g}$ per $100 \mathrm{cc}$ of solution) solution (1 CHO) vs tap water. Bottle positions were randomized daily and intake was measured every $24 \mathrm{~h}$. The rats were maintained on ad lib food, and no drugs were delivered at any time. Then, following a second 2-week rest period with ad lib food and water available, seven daily two bottle preference tests were conducted using $0.01 \mathrm{~g}$ of-quinine hydrochloride $(.01 \mathrm{Q})$ per $100 \mathrm{cc}$ of solution vs $0.001 \mathrm{~g}$ quinine per $100 \mathrm{cc}$ solution $(.001 \mathrm{Q})$. Bottle positions were randomized daily and intake measured every $24 \mathrm{~h}$. Again, ad lib food was available and no drugs were delivered at any time.

\section{Results and Discussion}

\section{Histology}

The lesions were extensive in both Groups CP and CNP. Most of the midline tissue from the anterior pole to the genu of the corpus collosum was destroyed, with the lesions extending about $1 \mathrm{~mm}$ lateral to the midline and from 2 to $4 \mathrm{~mm}$ below the dorsal surface of the cortex, including the pre- and subgenual areas. In Group $\mathrm{CP}$, three of seven rats received lesions severing 


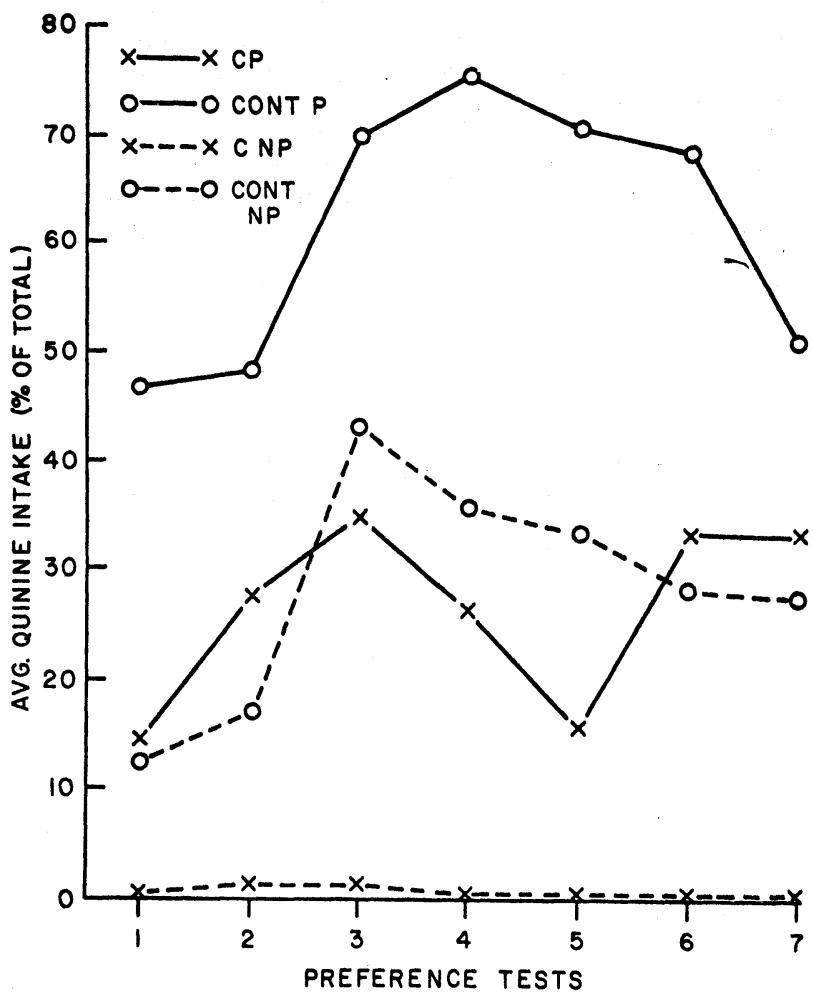

Fig. 3. Average intake of the more bitter (.01) quinine solution relative to total fluid (.01 plus .001 quinine) ingested in seven two-bottle preference tests.

the anterior corpus collosum and slightly damaging the dorsal septal area on both sides as well. The lesions were reasonably symmetrical bilaterally.

\section{Sugar Solution Tests}

No differences among groups were seen in sugar solution vs tap water tests. All rats consumed between $80 \%$ and $95 \%$ of their total fluid intake from the $1 \mathrm{CHO}$ bottles, averaging between 50 and $60 \mathrm{cc}$ daily while ingesting about 5 to $10 \mathrm{cc}$ of tap water daily. No trends appeared over the 5 days of testing indicating any change on the high relative preference for the sugar solution.

\section{Quinine Solution Tests}

The rats demonstrated a clear capability to discriminate between bitter solutions. The overall intake of the more bitter solution, .01 Q, was about $27 \%$, well below the chance level of 50\%. This result is in accord with previous demonstrations (Trafton \& Marques, 1971), that neither morphine intake experience nor cingulate cortex lesions are associated with taste discrimination deficits, at least for bitter solutions. However, the group patterns of quinine intake clearly show that previous morphine experience affects the relative amounts ingested. Figure 3 shows the intake curves for the seven daily preference tests. This figure is essentially a duplication of Fig. 1 and indicates that rats that preferentially drink more morphine also prefer the more bitter quinine solution $(.01 \mathrm{Q})$ to a greater extent. Nonlesioned, premedicated animals (Group ContP) average about $60 \% \quad .01 \mathrm{Q}$, and lesioned, nonpremedicated animals (Group CNP) won't ingest $.01 \mathrm{Q}$ at all, relative to total intake. Only one animal in the latter group ever ingested a measurable amount of $.01 \mathrm{Q}$. The median intake of .01 Q for Group ContP $(57 \%)$ is reliably higher than either Group CP or Group ConNP (28\% and 30\%, respectively, $p<.05$ ) and Group ContNP's median intake of $0 \%$ is reliably lower $(p<.001)$ than that of any other group.

The most obvious interpretation of the quinine intake patterns involves secondary reinforcement. By definition, rats preferentially selecting the bitter morphine solutions are demonstrating that morphine is a reinforcer. Thus, the bitter taste of the solution is a potential secondary reinforcer, and those animals which select morphine to the greatest extent also select the more bitter of two quinine solutions. And the effect seems to be a strong one, since no decrease in $.01 \mathrm{Q}$ intake is seen for seven consecutive tests. Stolerman and Kumer (1972) also report strong secondary reinforcement effects using rats when quinine is substituted for morphine, both before and after morphine abstinence.

The mechanism whereby cingulate lesions reduce morphine intake remains obscure. Lesioned animals show no general affective dullness, at least as reflected by preferential sugar solution intake. Bitter tastes associated with morphine intake apparently become secondary reinforcers in lesioned and nonlesioned animals alike, at least to the extent that such animals can be induced to drink morphine.

\section{REFERENCES}

Bard, P., \& Mountcastle, V. B. Some forebrain mechanism involved in expression of rage with special reference to suppression of angry behavior. Research Publication, Association for Research in Nervous \& Mental Disease, 1948, 27, 362-404.

Deneau, G., Yanagita, T., \& Seevers, M. H. Self-administration of psychoactive substance by the monkey. Psychopharmacologia, 1969, 16, 30-48.

Foltz, E. L. Modification of morphine withdrawal by frontal lobe cingulum lesions. In L. von Bogaert and J. Radermeker (Eds.), First international congress of neurological sciences. London: Pergamon Press, 1959.

Foltz, E. L., \& White, L. E. Experimental cingulumotomy and modification of morphine withdrawal. Journal of Neurosurgery, 1957, 14, 655-673.

Fox, S. S., Kimble, D. P., \& Lickey, M. E. Comparison of caudate nucleus and septal-area lesions on two types of avoidance behavior. Journal of Comparative \& Physiological Psychology, 1964, 58, 380-386.

Nichols, J. R. How opiates change behavior. Scientific American, $1965,212,80-88$. 
Nichols, J. R., \& Davis, W. M. Drug Addiction: II. Variation of addiction. Journal of American Pharmaceutical Association, Scientific Edition, 1959, 48, 259-262.

Nichols, J. R., Headlee, C. P., \& Coppock, H. W. Drug addiction: I. Addiction by escape training. Journal of American Pharmaceutical Association, Scientific Edition, 1956, 45, 788-791.

Smith, W. K. The results of ablation of the cingular region of the cerebral cortex. Federation Proceedings, 1944, 3, 42-43.

Stolerman, I. P., \& Kumar, R. Preferences for morphine in rats: Validation of an experimental model of dependence. Psychopharmacologia, 1970, 17, 137-150.

Thomas, G. J., \& Slotnick, B. M. Effects of lesions in the cingulum on maze learning and avoidance conditioning in rats. Journal of Comparative \& Physiological Psychology, 1962, 55, 1085-1091.
Trafton, C. L. Effects of lesions in the septal area and cingulate cortical areas on conditioned suppression of activity and avoidance behavior in rats. Journal of Comparative \& Physiological Psychology, 1967, 63, 191-197.

Trafton, C. L., \& Marques, P. R. Effects of septal area and cingulate cortex lesions on opiate addiction behavior in rats. Journal of Comparative \& Physiological Psychology, 1971, 75, 277-285.

(Received for publication September 10, 1973; accepted October 15, 1973.) 